\title{
The voluntary intake of hay and silage by lactating cows in response to ruminal infusion of acetate or propionate, or both, with or without distension of the rumen by a balloon
}

\author{
BY J. N. MBANYA*, M. H. ANIL† AND J. M. FORBES $\ddagger$ \\ Department of Animal Physiology and Nutrition, University of Leeds, Leeds LS2 $9 J T$
}

(Received 1 March 1991-Accepted 21 January 1992)

\begin{abstract}
In order to test the hypothesis that negative feedback signals from abdominal receptors are integrated in an additive manner in the control of voluntary food intake, cows with rumen fistulas were given intraruminal infusions of sodium acetate or sodium propionate, or both, with or without distension of the rumen by balloon. Intakes were monitored during the $3 \mathrm{~h}$ experimental period and for $2 \mathrm{~h}$ after and samples of rumen fluid were taken for estimation of short-chain fatty acid concentrations and osmolality. Six cows in mid-lactation were fed on hay and concentrates and given, into the rumen, 5.5 mol sodium acetate, $5.2 \mathrm{~mol}$ sodium propionate and $7.5 \mathrm{I}$ of distension. Compared with the control (water infusion), neither acetate, propionate nor distension significantly depressed hay intake when given separately. When given in combination, however, the following significantly depressed intake during the $3 \mathrm{~h}$ treatment period: propionate + distension, acetate + distension, acetate + propionate + distension. Seven cows in early lactation were fed on silage and concentrates and given, into the rumen, 9.0 mol sodium acetate, 4.0 mol sodium propionate and 10.0 litres of distension. Again, none of the three given alone depressed silage intake to a significant extent during the $3 \mathrm{~h}$ treatment period, whereas the following combinations had a significant effect: propionate + distension, acetate + distension, acetate + propionate + distension. Basal rumen osmolalities were similar for the two types of feed but infusion of the sodium salts caused a very much greater increase with silage than with hay. The results are discussed with regard to the implications for our understanding of the control of voluntary intake and the likely role of chemo-, osmo- and mechano-receptors.
\end{abstract}

Voluntary intake: Intraruminal infusions: Volatile fatty acids: Rumen distension: Dairy cows

During the last 30 years a considerable amount of work has been done to establish the role of metabolic and physical factors in the control of food intake in ruminant animals, and there is now adequate evidence that end-products of carbohydrate fermentation and distension of the rumen are involved in limiting intake. Intraruminal infusion of acetate over periods of several hours depressed hay intake in cattle (Montgomery et al. 1963; Bhattacharya \& Warner, 1968; Anil et al. 1993) and sheep (Baile \& McLaughlin, 1970; Bergen, 1972). Infusion of propionate in the rumen depressed feed intake by cattle (Montgomery et al. 1963; Anil et al. 1993) and sheep (Ternouth, 1967). However, most work has used salts of these acids and there is considerable doubt as to whether their effects are due to the acids themselves or to osmolality. Distension of the rumen depressed forage intake in cattle (Campling \& Balch, 1961; Anil et al. 1993). However, even at supraphysiological levels, none of these treatments completely prevents feeding and it is unlikely that either rumen volatile fatty acids (VFA) production or distension are entirely responsible for terminating normal feeding (Campling, 1970; Forbes, 1986).

It is likely that the effects of the changes that occur in the rumen during a meal, such as

* Present address: Institute of Animal Research, Bambui, Cameroon.

$\dagger$ Present address: Department of Meat Science, University of Bristol, Langford, Bristol BS18 7DY.

$\ddagger$ For reprints. 
production of VFA, changes in $\mathrm{pH}$, osmolality and rumen distension, may be interpreted as a whole by the brain to induce satiety. The effects of feedback signals have been suggested to be additive in sheep (Adams \& Forbes, 1981).

These investigations have now been extended to cattle in the present study in which the combined effects of ruminal infusions of acetate or propionate, or both, and rumen distension on the voluntary intake of hay or silage by lactating dairy cows have been examined. Brief accounts of the present work have already been published (Anil et al. 1987; Mbanya et al. 1989).

\section{MATERIALS AND METHODS}

The methods used were generally the same as those described by Anil et al. (1993).

Rumen-fistulated Friesian cows were kept in individual stalls and used in $2 \times 2 \times 2$ factorial experiments. Forage was available at all times, including a daily period of group exercise in a small yard, which meant that daily intakes could not be recorded. The treatments imposed involved all combinations of infusions of sodium acetate (Ac), infusions of sodium propionate $(\mathrm{Pr})$ and distension of a balloon (Dist) in the rumen as follows: water (control), $\mathrm{Ac}, \mathrm{Pr}, \mathrm{Dist}, \mathrm{Ac}+\mathrm{Pr}, \mathrm{Ac}+\mathrm{Dist}, \mathrm{Pr}+\mathrm{Dist}, \mathrm{Ac}+\mathrm{Pr}+\mathrm{Dist}$. Treatments were applied from 11.00 to 14.00 hours and at least $48 \mathrm{~h}$ elapsed between successive treatments, which were given in a partial Latin square design. Fresh forage was offered at the start of treatment and refusals were weighed at the end of the $3 \mathrm{~h}$ treatment period and again $2 \mathrm{~h}$ later. Rumen fluid samples were taken just before the start of treatment and $0.5,1,2,3,4$ and $5 \mathrm{~h}$ later. The samples were stored at $-20^{\circ}$ and later analysed for VFA by gas -liquid chromatography and for osmolality by freezing-point depression after centrifugation to remove all particulate matter. The results were analysed using analysis of variance (Statistical Analysis System, 1982) for the effects of Ac, Pr, Dist, animal and date and for first-order interactions between Ac, Pr and Dist.

\section{Expt 1}

Six cows in mid-lactation (mean milk yield, $21 \mathrm{~kg} / \mathrm{d}$ ) and 2 months pregnant were offered ryegrass (Lolium perenne $\mathrm{L}$.) hay ad lib. and a daily total of $7 \mathrm{~kg}$ concentrate ration (fresh weight) given in equal portions at morning (07.00 hours) and afternoon ( 16.00 hours) milking. The composition of the feeds is given in Table 1. On each of eight experimental days each cow was given a different combination of treatments, with at least $2 \mathrm{~d}$ between successive treatments. The experiment was then repeated over a further eight experimental days. The treatments were: Ac, $5.5 \mathrm{~mol}$; Pr, $5.2 \mathrm{~mol}$ (both in 4.5 litres water); Dist, 7.5 litres of balloon inflation. These levels were shown in previous work to have small depressing effects on hay intake (Anil et al. 1993).

\section{Expt 2}

Seven cows in the second and third months of lactation (mean milk yield, $25 \mathrm{~kg} / \mathrm{d}$ ) were offered grass silage ad lib. and $3.5 \mathrm{~kg}$ concentrate with $2.5 \mathrm{~kg}$ sugar-beet pulp (fresh weights) given in two equal portions at morning and afternoon milking. The experiment was carried out over eight experimental days and was not repeated. The treatments were: Ac, $9.0 \mathrm{~mol}$; Pr, $4.0 \mathrm{~mol}$ (both in 4.5 litres water); Dist, 10.0 litres of balloon inflation. These levels were shown in previous work to have small depressing effects on silage intake (Anil et al. 1993).

\section{RESULTS}

\section{Expt 1}

Voluntary intake of hay. Mean dry matter (DM) intakes of hay are given in Table 2. There was a significant overall depressing effect of Ac on intake during infusion $(2.87$ v. 2.48 ; $P=0.01)$, whereas the effect of Dist was not quite significant $(2.80 v .2 .55 ; P<0.07)$ and 
Table 1. Composition of feeds

\begin{tabular}{|c|c|c|c|c|}
\hline $\begin{array}{l}\text { No. of samples } \\
\text { (analysed in duplicate)... }\end{array}$ & $\begin{array}{c}\text { Concentrate } \\
5\end{array}$ & $\begin{array}{l}\text { Sugar-beet } \\
\text { pulp } \\
5\end{array}$ & $\begin{array}{c}\text { Hay } \\
10\end{array}$ & $\begin{array}{l}\text { Silage } \\
18\end{array}$ \\
\hline Dry matter (DM) $(\mathrm{g} / \mathrm{kg})$ & 883 & 909 & 906 & 196 \\
\hline Crude protein* (g/kg DM) & 167 & 103 & 138 & 151 \\
\hline MAD fibre (g/kg DM) & 98 & 152 & 386 & 393 \\
\hline Diethyl ether extract (g/kg DM) & 21 & 11 & 25 & 43 \\
\hline Ash (g/kg DM) & 43 & 76 & 47 & 87 \\
\hline
\end{tabular}

MAD fibre, modified acid-detergent fibre.

* Nitrogen $\times 6.25$.

Table 2. Expt l. Mean hay intake ( $k g$ dry matter (DM)) by lactating cows given combinations of acetate $(A c)$, propionate $(P r)$ and distension (Dist) in the rument

(Mean values for seven determinations)

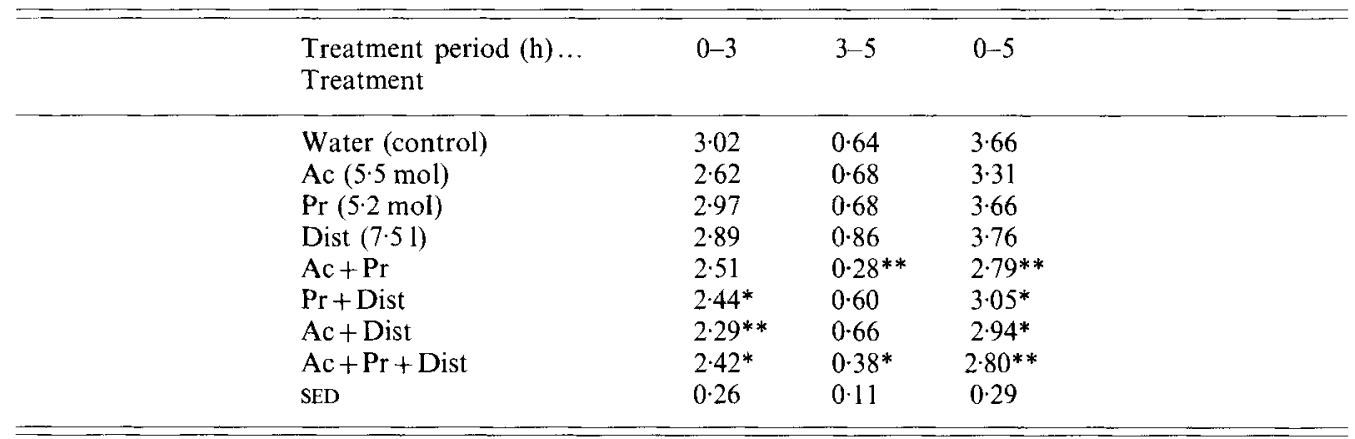

SED, standard error of the difference between treatment means.

Mean values were significantly different from those for water: * $P<0.05,{ }^{* *} P<0.01$.

$\dagger$ For details of treatments and procedures, see p. 714.

there was no apparent effect of $\operatorname{Pr}(2.72 v .2 .62 ; P=0.46)$. None of the first-order interactions was significant $(P>0 \cdot 39)$. There were significant carry-over effects of Ac $(P<0.01)$ and $\operatorname{Pr}(P<0.001)$ during the $2 \mathrm{~h}$ after the end of the treatment period, but again there were no significant interactions.

When the eight treatments were considered separately, those $3 \mathrm{~h}$ intakes which were significantly $(P<0 \cdot 05)$ lower than control intakes were: $\mathrm{Ac}+$ Dist, $\mathrm{Pr}+\mathrm{Dist}, \mathrm{Ac}+$ $\mathrm{Pr}+$ Dist. There were significant $(P<0.05)$ carry-over effects during the $2 \mathrm{~h}$ periods after treatment following $\mathrm{Ac}+\mathrm{Pr}$ and $\mathrm{Ac}+\mathrm{Pr}+\mathrm{Dist}$.

$V F A$ concentrations in rumen fluid. Mean acetate, propionate and butyrate concentrations in rumen fluid from 0.5 to $3 \mathrm{~h}$ and 4 to $5 \mathrm{~h}$ are shown in Table 3. The Ac and Ac + Dist treatments caused a significant $(P<0.05)$ increase in rumen fluid acetate concentration during the $3 \mathrm{~h}$ treatment period, while with treatments including a combination of $\mathrm{Ac}+\mathrm{Pr}$ the increase in acetate concentration in rumen fluid just failed to reach significance. During the $2 \mathrm{~h}$ post-treatment period, acetate concentration remained slightly higher than the control for the Ac and Ac+Dist treatments although this was not significant.

Administering Pr either separately or in combination with Ac or Dist, or both, increased propionate concentrations $(P<0.05)$ during the three periods and tended to decrease acetate concentration in rumen fluid. Distension of the rumen had no effect on acetate and 
Table 3. Expt 1. Effects of ruminal administration of acetate $(A c)$, propionate $(P r)$ and distension (Dist) on volatile fatty acid concentrations and osmolalities in rumen fluid of cows fed on hay

(Mean values for no. of observations/cow shown)

\begin{tabular}{|c|c|c|c|c|c|c|}
\hline \multirow{3}{*}{$\begin{array}{l}\text { Treatment period }(\mathrm{h}) \ldots \\
n\end{array}$} & \multicolumn{4}{|c|}{$\begin{array}{l}\text { Volatile fatty acids } \\
\qquad(\mathrm{mmol} / \mathrm{l})\end{array}$} & \multicolumn{2}{|c|}{$\begin{array}{c}\text { Osmolality } \\
(\mathrm{mosmol} / \mathrm{kg})\end{array}$} \\
\hline & \multicolumn{2}{|c|}{$\begin{array}{c}0 \cdot 5-3 \\
18\end{array}$} & \multicolumn{2}{|c|}{$\begin{array}{c}4-5 \\
12\end{array}$} & \multirow[t]{2}{*}{$0 \cdot 5-3$} & \multirow[t]{2}{*}{$4-5$} \\
\hline & $\mathrm{Ac}$ & $\mathrm{Pr}$ & $\mathrm{Ac}$ & $\operatorname{Pr}$ & & \\
\hline Water (control) & $46 \cdot 4$ & $15 \cdot 2$ & $51 \cdot 5$ & $15 \cdot 4$ & 263 & 264 \\
\hline Ac & $68 \cdot 8^{*}$ & $14 \cdot 1$ & $65 \cdot 0$ & $12 \cdot 3$ & $229^{*}$ & 279 \\
\hline $\operatorname{Pr}$ & $43 \cdot 5$ & $27 \cdot 0^{*}$ & $43 \cdot 8$ & 25.6 & $292 *$ & 274 \\
\hline Dist & $49-9$ & $14 \cdot 1$ & $52 \cdot 2$ & $15 \cdot 1$ & $276^{*}$ & 266 \\
\hline$A c+\operatorname{Pr}$ & $60 \cdot 5$ & $27 \cdot 1^{*}$ & 47.6 & $22 \cdot 8$ & $316^{*}$ & 307 \\
\hline $\mathrm{Ac}+$ Dist & $69 \cdot 3^{*}$ & $15 \cdot 3$ & $66 \cdot 4$ & $14 \cdot 5$ & 309 & 279 \\
\hline $\operatorname{Pr}+$ Dist & $44 \cdot 7$ & $28 \cdot 9^{*}$ & $43 \cdot 9$ & $33 \cdot 7^{*}$ & 282 & 283 \\
\hline $\mathrm{Ac}+\operatorname{Pr}+\mathrm{Dist}$ & $61 \cdot 2$ & $29 \cdot 7 *$ & $56 \cdot 8$ & $28 \cdot 2^{*}$ & $318^{*}$ & 291 \\
\hline SED & $7 \cdot 3$ & $2 \cdot 9$ & $8 \cdot 3$ & $2 \cdot 9$ & $9 \cdot 0$ & 5.8 \\
\hline
\end{tabular}

SED, standard error of the difference between treatment means.

Mean values were significantly different from those for water (control): ${ }^{*} P<0.05$.

$\dagger$ For details of treatments and procedures, see p. 714.

propionate concentrations and butyrate was not affected by any treatment. Acetate concentration in rumen fluid was not correlated with hay intake whereas the latter was correlated with propionate concentration during the $0-3 \mathrm{~h}(r-0 \cdot 28, P<0 \cdot 05)$ and $0-5 \mathrm{~h}$ $(r-0.37, P<0.05)$ periods.

Osmolality of rumen fluid. Mean osmolalities from 0.5 to 3 and 4 to $5 \mathrm{~h}$ are shown in Table 3. During the treatment period the main effect of Ac was significant $(P<0.001)$, as was that of $\operatorname{Pr}(P<0.05)$. There was no main effect of Dist and no significant interactions between the effects of Ac, $\operatorname{Pr}$ and Dist. As expected, osmolality was higher when Ac $+\operatorname{Pr}$ was infused, compared with either given alone. There was no significant correlation between rumen osmolality and hay intake even when the results of treatments involving Dist were omitted.

Osmolality returned towards control values after the infusions finished, but the effects of Ac and Pr were still significant $(P<0 \cdot 05)$.

\section{Expt 2}

Voluntary intake of silage. DM intakes of silage are given in Table 4. The depressing effect of Ac on silage intake during the treatment period was significant $(1.24$ v. $0.99 ; P<0.05)$, as were the effects of $\operatorname{Pr}(1.23 v .1 .00 ; P<0.05)$ and Dist $(1.29 v .0 .92 \mathrm{~kg} \mathrm{DM} ; P<0.01)$. None of the first-order interactions was significant but with both Ac+Dist and $\mathrm{Pr}+$ Dist the depression in intake was approximately twice the sum of the separate effects.

When the data were analysed with the eight combinations as separate treatments those $3 \mathrm{~h}$ intakes which were significantly lower $(P<0.05)$ than control intakes were: Ac + Dist, $\operatorname{Pr}+$ Dist, $\mathrm{Ac}+\operatorname{Pr}+$ Dist. During the $2 \mathrm{~h}$ after treatment, intakes were still significantly depressed following the Ac, $\mathrm{Ac}+\mathrm{Pr}, \mathrm{Ac}+\mathrm{Dist}, \mathrm{Pr}+\mathrm{Dist}, \mathrm{Ac}+\mathrm{Pr}+$ Dist treatments.

$V F A$ concentrations in rumen fluid. The mean values for acetate, propionate and butyrate concentrations are given in Table 5. The administration of $\mathrm{Ac}+\mathrm{Pr}+\mathrm{Dist}$ together 
Table 4. Expt 2. Mean silage intake by lactating cows given combinations of acetate $(A c)$, propionate (Pr) and distension (Dist) in the rumen ( $k g$ dry matter $(D M)) \dagger$

(Mean values for seven determinations)

\begin{tabular}{llll}
\hline $\begin{array}{l}\text { Treatment period }(\mathrm{h}) \ldots \\
\text { Treatment }\end{array}$ & $0-3$ & $3-5$ & $0-5$ \\
& & & \\
\hline Water (control) & 1.40 & 0.77 & $2 \cdot 17$ \\
Ac $(9 \cdot 0 \mathrm{~mol})$ & 1.20 & $0.44^{*}$ & 1.64 \\
Pr (4.0 mol) & 1.24 & 0.59 & 1.83 \\
Dist (10.01) & 1.25 & 0.84 & $2 \cdot 10$ \\
Ac +Pr & 1.23 & $0.41^{*}$ & 1.64 \\
Pr+Dist & $0.93^{*}$ & $0.54^{* *}$ & 1.47 \\
Ac + Dist & $0.93^{*}$ & $0.45^{*}$ & $1.38^{*}$ \\
Ac + Pr + Dist & $0.51^{* *}$ & $0.05^{* *}$ & $0.56^{* *}$ \\
SED & 0.20 & 0.27 & 0.35 \\
\hline
\end{tabular}

SED, standard error of the difference between treatment means.

Mean values were significantly different from those for water: $* P<0.05,{ }^{* *} P<0.01$.

$\uparrow$ For details of treatments and procedures, see p. 714 .

Table 5. Expt 2. Effects of ruminal administration of acetate $(A c)$, propionate (Pr) and distension (Dist) on volatile fatty acid concentrations and osmolalities in rumen fluid of cows fed on silage $\dagger$

(Mean values for no. of observations/cow shown)

\begin{tabular}{|c|c|c|c|c|c|c|}
\hline \multirow{3}{*}{$\begin{array}{l}\text { Treatment period }(\mathrm{h}) \ldots \\
n\end{array}$} & \multicolumn{4}{|c|}{$\begin{array}{l}\text { Volatile fatty acids } \\
\qquad(\mathrm{mmol} / \mathrm{l})\end{array}$} & \multicolumn{2}{|c|}{$\begin{array}{l}\text { Osmolality } \\
\text { (mosmol/kg) }\end{array}$} \\
\hline & \multicolumn{2}{|c|}{$\begin{array}{c}0 \cdot 5-3 \\
21\end{array}$} & \multicolumn{2}{|c|}{$\begin{array}{l}4-5 \\
14\end{array}$} & \multirow[t]{2}{*}{$0 \cdot 5-3$} & \multirow[t]{2}{*}{$4-5$} \\
\hline & $\mathrm{Ac}$ & $\operatorname{Pr}$ & Ac & $\operatorname{Pr}$ & & \\
\hline Water (control) & $54 \cdot 1$ & $19 \cdot 5$ & $51 \cdot 4$ & $19 \cdot 3$ & 289 & 278 \\
\hline Ac & $90 \cdot 0$ & $15 \cdot 3$ & $71 \cdot 5$ & $13 \cdot 9$ & 395 & 348 \\
\hline $\operatorname{Pr}$ & $52 \cdot 3$ & $32 \cdot 2$ & $45 \cdot 8$ & 26.9 & 330 & 306 \\
\hline Dist & $64 \cdot 1$ & $20 \cdot 3$ & $59 \cdot 4$ & $17 \cdot 5$ & 285 & 284 \\
\hline $\mathrm{Ac}+\mathrm{Pr}$ & 63.9 & $39 \cdot 1$ & $79 \cdot 3$ & $40 \cdot 8^{*}$ & $452^{*}$ & $359^{*}$ \\
\hline $\mathrm{Ac}+\mathrm{Dist}$ & $77 \cdot 7$ & $21 \cdot 5$ & $73 \cdot 1$ & $19 \cdot 9$ & $444^{*}$ & 312 \\
\hline Pr + Dist & $51 \cdot 9$ & $40 \cdot 9$ & $48 \cdot 5$ & $26 \cdot 7$ & 339 & 310 \\
\hline $\mathrm{Ac}+\mathrm{Pr}+$ Dist & $129 \cdot 3 * *$ & $63 \cdot 0^{* *}$ & $88 \cdot 6^{* *}$ & $38 \cdot 1^{*}$ & $534^{*}$ & $377^{*}$ \\
\hline SED & $18 \cdot 2$ & $10 \cdot 6$ & $12 \cdot 8$ & $7 \cdot 2$ & $50 \cdot 5$ & $23 \cdot 8$ \\
\hline
\end{tabular}

SED, standard error of the difference between treatment means.

Mean values were significantly different from those for water: ${ }^{*} P<0.05,{ }^{* *} P<0.01$.

$\dagger$ For details of treatments and procedures, see p. 714 .

significantly increased both rumen fluid acetate and propionate concentrations compared with the control during the $0.5-3 \mathrm{~h}, 3-5 \mathrm{~h}$, and $4-5 \mathrm{~h}$ periods. Silage intakes were not significantly correlated with mean acetate or propionate concentrations in the rumen during any of the three periods. The treatments $\mathrm{Ac}$, Ac + Dist and $\mathrm{Pr}, \mathrm{Pr}+\mathrm{Dist}$ caused nonsignificant increases in acetate and propionate concentrations respectively during the three periods. Butyrate concentrations remained stable and unaffected by treatments. 
Osmolality of rumen fluid. Mean osmolalities for $0.5-3 \mathrm{~h}$ and $4-5 \mathrm{~h}$ are shown in Table 5. The main effect of Ac during the treatment period was significant $(P<0.001)$, while that of Pr did not reach significance $(P<0 \cdot 10)$. There was no effect of Dist and no significant interactions between the effects of Ac, Pr and Dist. The increase in osmolality during infusion was, as expected, greater when both Ac and Pr were infused than when either was given alone.

The most striking feature of these results is that although the osmolality before the start of infusion was only slightly greater with silage than with hay (Expt 1) the increases during treatment were several-fold greater. Larger amounts of Ac were infused in Expt 2 than in Expt $1(9.0$ v. $5.5 \mathrm{~mol} \mathrm{Ac} / 3 \mathrm{~h})$ while the amount of $\mathrm{Pr}$ given $(4.0 \mathrm{~mol} / 3 \mathrm{~h})$ was less than that given in Expt $1(5 \cdot 2 \mathrm{~mol} / 3 \mathrm{~h})$. In all treatments which involved Ac, osmolality rose quickly to peak at $1 \mathrm{~h}$, then declined at $2 \mathrm{~h}$ to be followed by a second, but smaller, peak at the end of infusion.

There was no significant correlation between individual values of rumen osmolality and corresponding silage intakes, even when results from treatments involving Dist are omitted.

\section{DISCUSSION}

The results from the present study confirm previous findings (Adams \& Forbes, 1981) that treatments which do not have a significant effect on food intake when given separately in the rumen cause significant depressions in intake when given together.

In previous experiments (Anil et al. 1993) it had been shown that levels of treatment (Ac, Pr, Dist) above the physiological range did not cause feeding to cease, so that no single factor could be seriously proposed as the only controller of feeding. We can now speculate that the many small changes occurring in relation to feeding, including intestinal concentrations and abdominal temperature, act together to inform the central nervous system which integrates the incoming signals in an approximately additive manner. If this is true then it has important implications. For example, rather than envisaging a static relationship between the degree of distension of the rumen and food intake, we should think of a dynamic situation in which the degree of distension required to inhibit feeding will depend on the extent to which the other families of abdominal receptors are being stimulated.

Increased rates of utilization of VFA would be expected to lead to reduced concentrations and, therefore, reduced stimulation of VFA-sensitive receptors. A greater degree of rumen distension could, therefore, be accommodated before the total of the signals from abdominal organs became satiating. Tulloh (1968) observed that lactating cows had a greater volume of rumen contents than non-lactating cows and Weston (1984) found that more rapidly growing sheep had greater rumen fill, both these examples being with feeds whose voluntary intake would be expected to be 'physically' limited. Casein infusion into the duodenum of sheep fed on a low-protein forage increased feed intake and rumen fill and led Egan (1970) to state 'that a mechanism of interacting physiological and metabolic factors may be involved throughout the whole range of diets utilized by ruminants, and that there is not simply a switch-over to metabolic regulation at a point where disposal of indigestible bulk is no longer an embarrassment or a limitation to the total digestible energy intake'. This view is entirely consistent with the concept of additivity of feedback signals in the control of feed intake which the currently-reported results support.

The ways in which the sodium salts of VFA affect intake have been discussed by Anil et al. (1993) and it is entirely possible that most, if not all, the effects of Ac and Pr observed in these experiments were due to their effects on the osmolality of rumen fluid. There have been brief reports of osmotic effects on receptors in the rumen wall but the results have been 
very variable (B. F. Leek, personal communication). However, Ternouth \& Beattie (1971) and Carter \& Grovum (1988) have clearly demonstrated effects of ruminal infusions on feeding in sheep which are related to rumen osmolality rather than to that of abomasal contents or blood plasma. A particularly striking observation in the experiments reported here is the greatly elevated osmolalities when salts of VFA were infused into the rumen of cows fed on silage (Expt 2) compared with hay (Expt 1), despite the lack of such large differences in the ruminal concentration of VFA. This suggests that sodium was being retained in the rumen to a greater extent with silage than with hay, but previous work under the same conditions (Anil et al. 1993) showed similar concentrations during infusion for hay and silage; $\mathrm{pH}$ was also unaffected by diet or infusion.

A difference in osmolality between hay and silage is not the only reason for differences in intake between the two feeds as silage intakes during water (control) and Dist treatments were considerably lower than for hay despite the relatively small differences in rumen osmolality. Further, even when results from treatments involving Dist were omitted there were no significant correlations between the osmolality of rumen fluid and voluntary intake.

If a major route for effects of sodium salts of VFA on feeding is by elevation of the osmolality of rumen fluid, then it would be expected that Ac would have additive effects with $\mathrm{Pr}$ in the experiments reported here; this was not obviously the case in either Expt 1 (Tables 2 and 3) or Expt 2 (Tables 4 and 5) even though osmolality was much higher during the combined infusion of the two salts than with either given alone. We cannot explain why intake was not further depressed with the treatment with Ac and Pr, compared with Ac alone.

Dist had no effect on the concentration of VFA, nor the osmolality of rumen contents, and it can be concluded that the effect of this treatment on food intake was by stimulation of mechano-receptors in the rumen wall.

In conclusion, within physiological conditions a single signal in the rumen is unlikely to be adequate to influence feeding behaviour seriously in the lactating dairy cow. Rather, it appears that satiety can be induced by the additive effects of many negative feedback signals and that daily food intake will depend on the balance between such negative effects and the positive influences of nutrient utilization.

This work was supported by a grant from the Agricultural and Food Research Council. J. N.M. was supported by the Cameroon Government. The authors are grateful to Roger Harrison for the feeding and management of the cows.

\section{REFERENCES}

Adams, G. B. \& Forbes, J. M. (1981). Additivity of effects of ruminal acetate and either portal propionate or rumen distension on food intake in sheep. Proceedings of the Nutrition Society 40, 44A.

Anil, M. H., Forbes, J. M.\& Mbanya, J. N. (1987). Additive effects of acetate, propionate and distension of the rumen on hay intake by lactating cows. Journal of Physiology 386, 61P.

Anil, M. H., Mbanya, J. N., Symonds, H. W. \& Forbes, J. M. (1993). Responses in the voluntary intake of hay or silage by lactating cows to intraruminal infusions of sodium acetate or sodium propionate, the tonicity of rumen fluid or rumen distension. British Journal of Nutrition 69, 699-712.

Baile, C. A. \& McLaughlin, C. L. (1970). Feed intake during volatile fatty acid injections into four gastric areas. Journal of Dairy Science 51, 1058-1063.

Bergen, W. G. (1972). Rumen osmolality as a factor in feed intake control in sheep. Journal of Animal Science 34, $1054-1060$.

Bhattacharya, A. N. \& Warner, R. G. (1968). Effect of propionate and citrate on depressed feed intake after intraruminal infusions of acetate in dairy cattle. Journal of Dairy Science 51, 1091-1093.

Campling, R. C. (1970). Physical regulation of voluntary intake. In Physiology of Digestion and Metabolism in the Ruminant, pp. 226-234 [A. T. Phillipson, editor]. Newcastle, England: Oriel Press. 
Campling, R. C. \& Balch, C. C. (1961). Factors affecting the voluntary intake of food by cows. British Journal of Nutrition 15, 523-530.

Carter, R. R. \& Grovum, W. L. (1988). Observations on how sodium chloride loading of the rumen depresses food intake in sheep. Proceedings of the Nutrition Society 47, 155A.

Egan, A. R. (1970). Nutritional status and intake regulation in sheep. 6. Evidence for variation in setting of an intake regulatory mechanism relating to the digesta content of the reticulorumen. Australian Journal of Agricultural Research 21, 735-746.

Forbes, J. M. (1986). The Voluntary Food Intake of Farm Animals. London: Butterworths.

Mbanya, J. N., Anil, M. H. \& Forbes, J. M. (1989). Combined effects of intraruminal application of acetate, propionate and distension on silage intake by dairy cows. Animal Production 48, 639.

Montgomery, M. J., Schultz, L. H. \& Baumgardt, B. R. (1963). Effect of intraruminal infusions of VFAs and lactic acid on voluntary hay intake. Journal of Dairy Science 48, 1380-1384.

Statistical Analysis Systems (1982). SAS User's Guide: Statistics. Cary, North Carolina: SAS Institute Inc.

Ternouth, J. H. (1967). A factor limiting the ruminant's voluntary consumption of silage. Journal of the Australian Institute of Agricultural Science 33, 263-264.

Ternouth, J. H. \& Beattie, A. W. (1971). Studies of the food intake of sheep at a single meal. British Journal of Nutrition 25, 153-164.

Tulloh, N. M. (1968). Physical studies of the alimentary tract of grazing cattle. IV. Dimensions of the tract in lactating and non-lactating cows. New Zealand Journal of Agricultural Research 9, 999-1008.

Weston, R. H. (1984). Rumen digesta load in relation to voluntary feed consumption and rumination in roughagefed young sheep. Canadian Journal of Animal Science 64, Suppl., 324-325. 